\title{
Through the Wall, Recognize Moving Targets Based on Micro- Doppler Signatures
}

\author{
Thamir Rashed Saeed, Mahmuod Hamza Al-Muifraje, Ghufran M. Hatem \\ Radar Research Group $\left(R^{2} G\right)$, Department of Electrical Engineering, University of Technology, Iraq
}

\begin{tabular}{l} 
Article Info \\
\hline Article history: \\
Received Jan 21, 2018 \\
Revised Jul 26, 2018 \\
Accepted Jul 29, 2018 \\
\hline Keyword: \\
Micro-doppler frequency \\
Object recognition \\
Through wall detection
\end{tabular}

\begin{abstract}
Radar is a promising device for detection and recognition of invisible moving objects, Where, the micro-Doppler frequency shift caused by moving the object's parts have been represented as an attractive feature in the recognition process. In spite of that, no thorough analysis of human movement by bicycle and no discriminate from the running one through the wall in the literature. This paper presents a mathematical model of bicycle movement, then, the recognition of moving objects through the wall. Where three human movements; walking, running and on a bicycle have been recognized through two types of wall wood and cork. The theoretical analysis and measured was given a recognition $98.7 \%$ for human walking on his feet, $99 \%$ of the passenger on a bicycle, and $98 \%$ of the person running have been achieved without walls. While, a $95.4 \%, 96.2 \%$, and $95 \%$ recognition have been gained from walking, moving by bicycle and running with wooden wall and $94 \%, 94.8 \%$, and $93.3 \%$ respectively with cork wall. $2.4 \mathrm{GHz}$ as a detector and SVM as classifier are used.
\end{abstract}

Copyright () 2018 Institute of Advanced Engineering and Science. All rights reserved.

\section{Corresponding Author:}

Thamir Rashed Saeed,

Department of Electrical Engineering,

University of Technology, Iraq.

Email: thamir_rashed@yahoo.com

\section{INTRODUCTION}

In the last decade, radar has developed as a promising innovative [1] for detecting and recognizing the moving objects behind the walls [2]-[4]. In this context, the walls are complex propagation environments that introduce refraction, attenuation, ringing and multipath to the radar signal [2]. Therefore, the knowledge of moving objects can be a useful tool in surveillance, security, military combat, search and rescue operations, medical fields, urban warfare, anti-terrorism, law enforcement, earthquake survivor detection, trapped human location, homeland security, and the concealed weapon detection [5]-[8]. In this context, the advantages of radar compared to the other sensors is the ability of operation in different environments [9]-[11].

The expected behavior of the illuminated moving objects by radar signal has modulated this signal at the received phase caused by the time-varying delay between the radar and that object. Than a Doppler frequency has been introduced caused by this motion, while, the micro-Doppler which is caused by micromotion-[2], [12]. In case of human as a non-rigid body, where his micro-motion is introduced by his parts; the arms, legs, torso, and others. All these parts are contributed to a unique signature caused by its microDoppler which is modulated on the main Doppler which is created by the torso [10]. Therefore, the recognition of moving objects is achieved by its micro-Doppler (MD) features, where, the micro-motion has a unique signature at different ranges [13], [14]. This signature will be reduced to minimize the efforts of digital signal processing applications [15]-[18]. It is often beneficial, the choice of the frequency of operation depends on the application, specifically on the barrier type, target position behind the wall, standoff requirement, and resolution requirements, all of which are somewhat interrelated [8]. 
As for the through-wall applications, which is represented an is appealing research area there is great research value for human detection and recognition using radar technology. Where, Lui et al. [19] studied the motion detection and recognition based on MD through the homogeneous non-magnetic walls, where they show that the signatures are unaltered as corroborated by Ram et al. In [20]. In this context, Chen et al. in [10], [21] presented a recognition study through two different $10 \mathrm{~cm}$-thick walls, concrete blocks and plastic, for medical application. In [6] was concentrated to the through the walls classification accuracy by using the support vector machine for S-band at long range. While [22], is extracted the effected micro signal by threshold segmentation, and the training phase is done by using SVM with accuracy is gained by $95.4 \%$.

However, despite these studies, there is still a gap in the distinction between the detection and the recognition through the wall for the running person from that whose moving by bicycle and there is no mathematical model of these movements. Indeed the increasing of the usage of the non-magnetic material like wood and cork as wall's insulation layer especially in the hospitals, while there is a gap in the research area of detection and recognition through these layers.

Therefore, this paper focuses on the recognition of the human activities through the wood and cork layers. Also, the mathematical analysis of the human moving by a bicycle is present. Then, the effect on the microwave propagation through this layer, and the recognition of the human movement have been presented

\section{MICRO-DOPPLER EFFECT IN RADAR [14]}

To analyze the moving object at point $\mathrm{P}$ with moving frequency $f v$ at distance $R$ with displacement Dv as shown in Figure 1, the mathematics of its micro-Doppler effect is;

The displacement function is

$D(t)=D_{v} \sin (2 \pi f v t) \cos \beta \cos \alpha_{p}$ (assuming $\alpha=0$ and $\left.\beta_{p}=0\right)$

The range function varies with time due to the target micro-motion is;

$$
R(t)=R+D(t)
$$

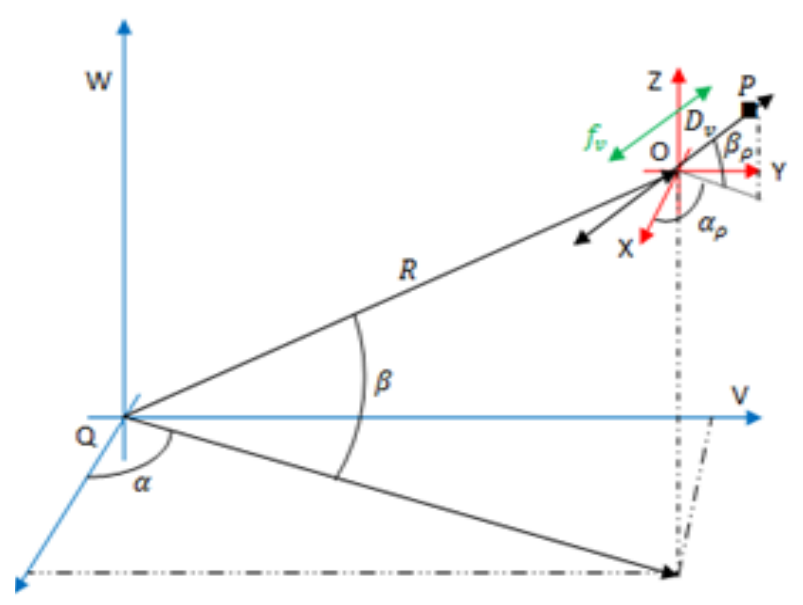

Figure 1. Geometry for radar and moving point object

The radar received signal becomes [1]

$$
\begin{aligned}
& s(t)=\rho e^{\left(j\left(2 \pi f_{o}+\varphi(t)\right)\right)} \\
& \varphi(t)=4 \pi \frac{R(t)}{\lambda}
\end{aligned}
$$

where; $\rho$ - backscattering coefficient.

$f_{o}$ - carrier frequency. 
$\lambda$ - carrier wavelength.

Substituting the equation of $\mathrm{R}(\mathrm{t})$ in equation (1), and then derive its phase to produce the micro-Doppler as;

$$
f_{m D}=\frac{W_{v} D_{v}}{\pi \lambda} \cos \beta \cos \alpha_{\rho} \cos \left(W_{v} t\right)
$$

In this context, the round-trip return time $\tau_{\mathrm{R}}$ for a target located at a range of $\mathrm{R}$ is given by [8];

$$
\tau_{R}=\frac{2 R}{c}
$$

\section{WALL EFFECTS}

In through-the-wall radar design and its return signal analysis, the properties of that wall represent critical factors which affected on the attenuation, dispersion, reflection, and refraction of the return signal and then on the Doppler signatures [23], [10]. The effect of the walls on the, Tx/Rx below X band, radar signals are concentrated in two points; the first one is the effect on the signal phase, this effect is simple and constant because of the wall is stationary. The second effect is on the maximum detectable range, where, the signal-tonoise ratio (S/R) of the MD signature is decrease caused by the wall attenuation [2], [24]. In this context, the properties of the wall which is produced the attenuation are; the permittivity $(\varepsilon)$, permeability $(\mu)$, and the conductivity $(\sigma)$, where, all these prosperities are varied on the frequency of the incident wave. If these material's properties are known, then the attenuation constant can be approximated as [23], [25];

$$
\alpha=\omega \sqrt{\varepsilon \mu \frac{\sqrt{1+\left(\frac{1}{\omega \varepsilon}\right)^{2}-1}}{2}}
$$

for low-lossy material as wood can approximate as

$$
\alpha=0.5 \sigma \sqrt{\frac{\mu}{\varepsilon}}=0.5 \sigma \sqrt{\frac{\mu_{o}}{\varepsilon=\varepsilon_{r} \varepsilon_{o}}}
$$

while the incident wave velocity through the material is[25];

$$
v=\frac{c}{\sqrt{\varepsilon_{r} \mu_{r} \frac{1+\sqrt{1+\left(\frac{\sigma}{\omega \varepsilon}\right)^{2}}}{2}}}
$$

where; $\varepsilon=\varepsilon_{r} \varepsilon_{o}, \omega=2 \pi f$,

$$
\begin{aligned}
& \mu_{r}=1 \text { for low }- \text { loss material like wood } \\
& \therefore \quad v=c / \sqrt{\varepsilon_{r}} \\
& \mu_{o}=4 \pi 10^{-7} \mathrm{H} / \mathrm{m} . \\
& \varepsilon_{o}=8.85418782 \times 10^{-12} \mathrm{~m}^{-3} \mathrm{~kg}^{-1} \mathrm{~s}^{4} \mathrm{~A}^{2}
\end{aligned}
$$

Observing the Doppler features of the reflected signal enables the clutter to be easily suppressed because, in general, traditional clutter elements such as walls, furniture, and other stationary objects will not exhibit a Doppler shift.

It is worth noting that, when the wall is constructed from the wood or glass or cork or drywall, the attenuation is relatively small. Consequently, the frequency selection is important for applications because the material properties are dependent on it. [23]. However, if a stationary target vibrates, rotates, or maneuvers, its structural parts are in motion, and these induce the micro-Doppler modulations. If there are $i=1,2, \ldots, N$ structures with $V r, i$ being the radial velocity of the $i_{t h}$ structure, the composite micro-Doppler signal has frequency components at $2 \mathrm{~V}_{\mathrm{r}, \mathrm{i}} \mathrm{f}_{\mathrm{o}} / \mathrm{c} \forall \mathrm{i}=1,2, \ldots, \mathrm{N}$, which are unique to the specific motional characteristics of the target.

Analysis of the micro-Doppler signatures in the joint time-frequency domain can provide useful information for target detection, classification, and recognition [8], [26]. Therefore, the micro-Doppler signatures from the scene are calculated by applying a time-frequency transforms, such as the Short-Time Fourier Transform (STFT) with a Gaussian window, to the scattered fields. Then, the computation of this transform is based on the proper sampling rate, while this sampling rate depends on the maximum frequency Doppler shift, where, it depends on the rate of motion [9]. 


\section{EXPERIMENTAL CASE STUDY}

The experimental work for detection and recognition of the human movements behind the wall have been done with the specific parameters as in Table 1, these parameters are;

Table 1. Experimental Parameters

\begin{tabular}{cccc}
\hline No. & Parameter & Quality & Types \\
\hline 1 & Wall thickness & $20 \mathrm{~cm}$ & wooden \\
2 & Body parts speed & $2-5 \mathrm{~m} / \mathrm{sec}$ & Human \\
3 & Dv & $0.01 \mathrm{~m}$ & \\
4 & $\mathrm{U}$ & $0 \mathrm{~m}$ & \\
5 & $\mathrm{~V}$ & $2-5 \mathrm{~m}$ & Human \\
6 & $\mathrm{~W}$ & $1.66 \mathrm{~m}$ & Human \\
7 & Carrier frequency & $2.4 \mathrm{Ghz}$ & \\
8 & BW & $400 \mathrm{Mhz}$ & Radar \\
9 & Sampling & 128 & Parameters[19] \\
10 & Ant. Polarization & Vertical & \\
11 & Sweep Time FMCW-Sawtooth & $0.5 \mathrm{msec}$ & \\
\hline
\end{tabular}

Figure 2.

The human body model has been based on the model which is presented in [7], [8], [9] as shown in

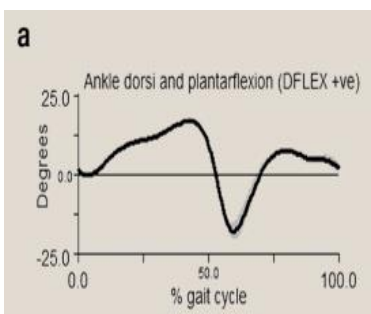

b

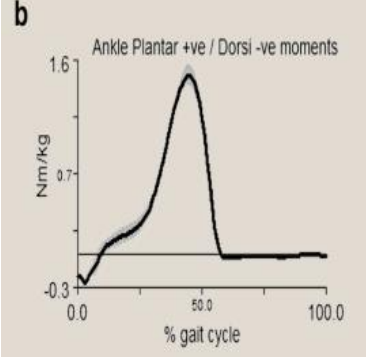

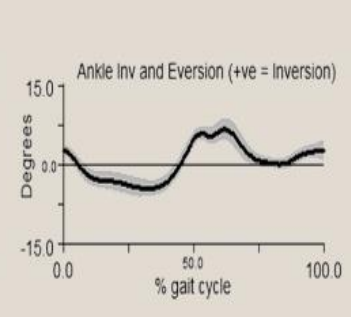

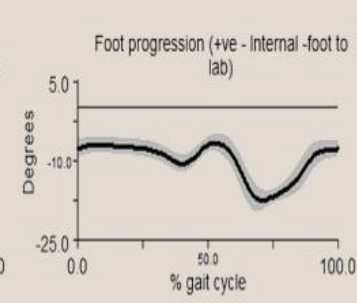

C

C Ankie joint power (frontal plane - tve

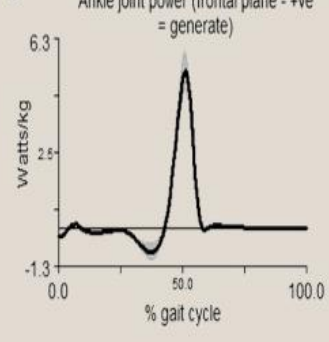

(a)Radial velocities for different body joints in one cycle

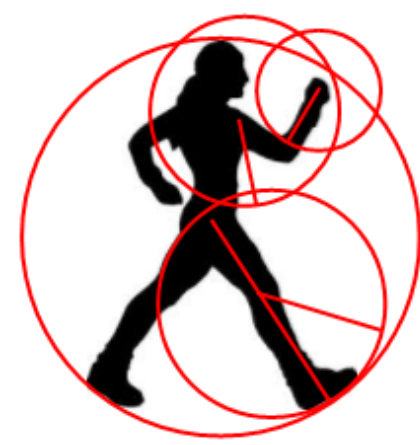

(b)Different moving body's parts

Figure 2. Human body's parts velocities

where; $R_{v}=$ relative velocity of cycle=average velocity/ height of the thigh $=3 / 0.83=3.6144$

$L_{c}=$ relative length of the cycle $=1.346 \sqrt{R_{v}}=2.5589$

$T_{c}=L_{c} / R_{v}$-- duration of walking cycle $=2.5589 / 3.6155=0.707 \mathrm{sec}$

$f_{\text {Doppler }}=2 v_{R} / \lambda_{c=}(32-80) \mathrm{Hz}$

$v_{R}$ - rate of motion $(2-5) \mathrm{m} / \mathrm{sec}$,

The sampling rate is directly proportional to the maximum speed observed. It follows that, for a range of speed of $2-5 \mathrm{~m} / \mathrm{s}$, the Doppler shift can vary significantly based on the operating frequency of the radar. For instance, using a $2.4 \mathrm{GHz}$ radar results in a Doppler shift of (32-80) Hz, which requires a sampling rate (64-160) samples/s. In this context, the model of the human moving on a bicycle as shown in Figure 3 is; The linear movement of lag= $D \mathrm{~m}$.

The circumference of a circle $C 1$ is related to $2 D \mathrm{~m}$.

$C 1=K C 2 \mathrm{~m} .=K \times \pi \times R \mathrm{~m}$.

The speed of bicycle $=Z \times K \times \pi \times R \mathrm{~m} / \mathrm{sec}$. 
where; $K$ - percent of $C 1 / C 2$.

$Z$ - no. of turn /sec.

$R$ - radius of the rear wheel.

$\mathrm{L}=\mathrm{u} \cos (\beta)+\mathrm{Y} \cos (\alpha)$

Then the Doppler frequency of the human moving on bicycle $=2 \times f \frac{\mathrm{V}}{\mathrm{C}}$

$$
\frac{2 f}{C} \frac{d}{d t} L(t) \cong \frac{f}{c} Z K C 2=6.315 Z K C 2 \mathrm{~Hz}
$$

\section{RESULTS AND DISCUSSION}

The experiments have been done in our laboratory by using an Ancortek Inc. S-band radar kit [27] as shown in Figure 4(a). Where from the results of these experiments, the ability of detection and recognition of the moving body behind the wooden wall is evident and shows in the Figures (5-9). Where three different human movements have been examined; Human walking, running and moving by the bicycle as explained in Figures (2,3), with two different walls; wooden and cork as in Figure 3 and 4.
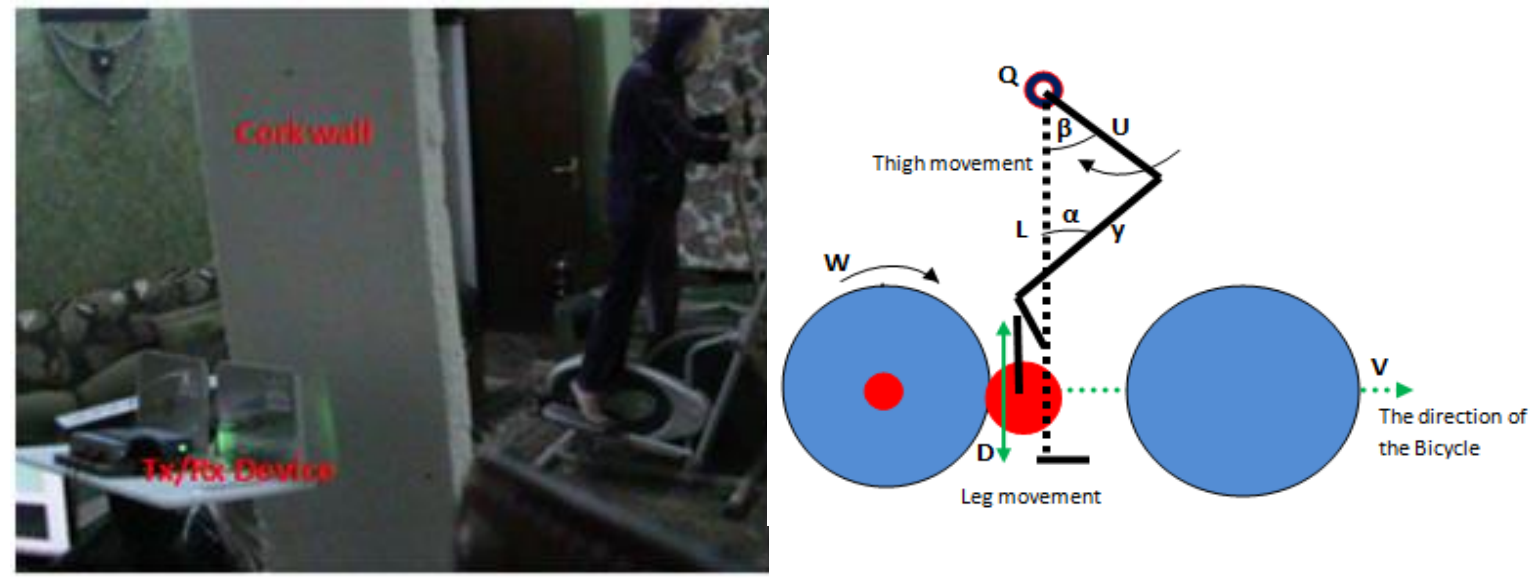

Figure 3. Human moving on bicycle model

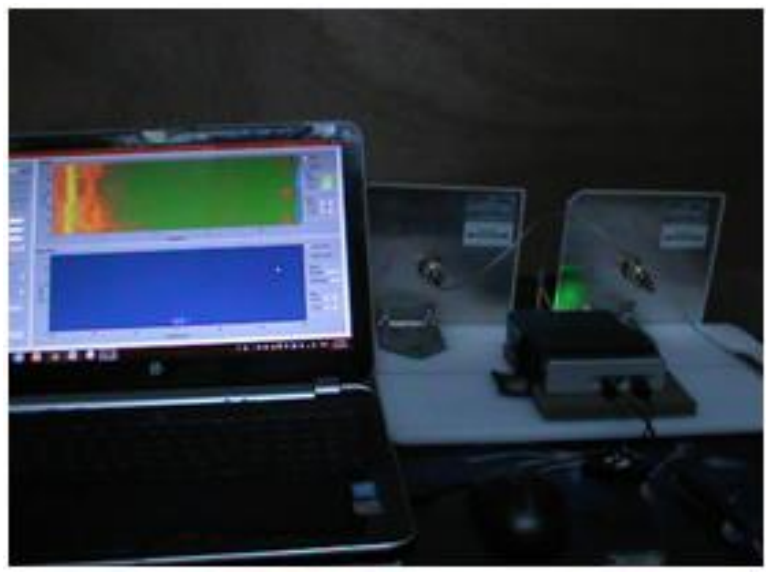

(a)Radar behind the wall

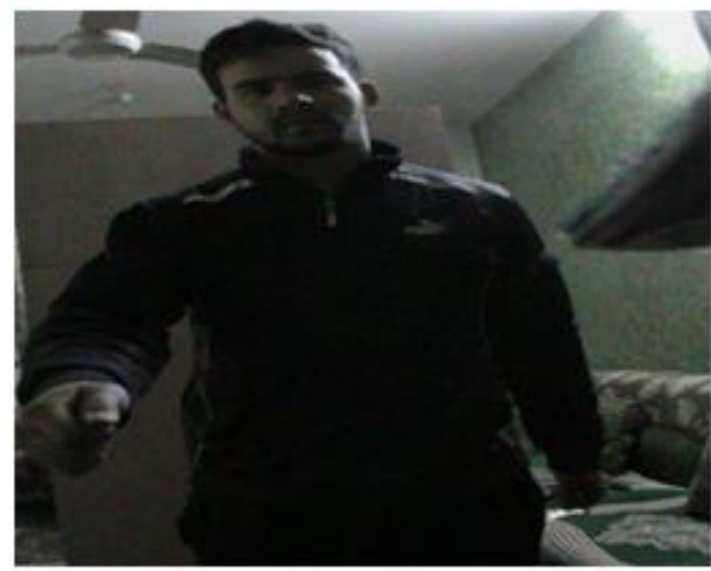

(b)Walking person on the other wall side

Figure 4. The experiment in libratory, (a) the radar in wooden wall side, (b) moving person in another wooden wall side

The moving Human body parts, radial velocities, and related Doppler frequencies are listed in the Table 2. 
Table 2. Human Body Parts Velocities and Related Doppler Frequencies

\begin{tabular}{ccc}
\hline H.B.P.* & Speed m/sec & Doppler frequency $(\mathrm{Hz})$ \\
\hline Hand speed & $-0.7-+2$ & $11.2-32$ \\
Knee & $-0.7-+2.1$ & $11.2-33.6$ \\
Ankle & $-0.2-+4.95$ & $3.2-79.2$ \\
Toe & $-0.8-+4.8$ & $12.8-76.8$ \\
\hline
\end{tabular}

In the beginning, the laboratory wall at $5.6 \mathrm{~m}$ from the radar. The power frequency intensity against range is shown in Figure 5(a), which is related to the laboratory wall and the response of the person in the laboratory without moving at $2.8 \mathrm{~m}$ from the radar. Also, the Doppler frequency range of that wall and person appears in the Figure 5(b), and it's clear the Doppler is zero because there is no motion.

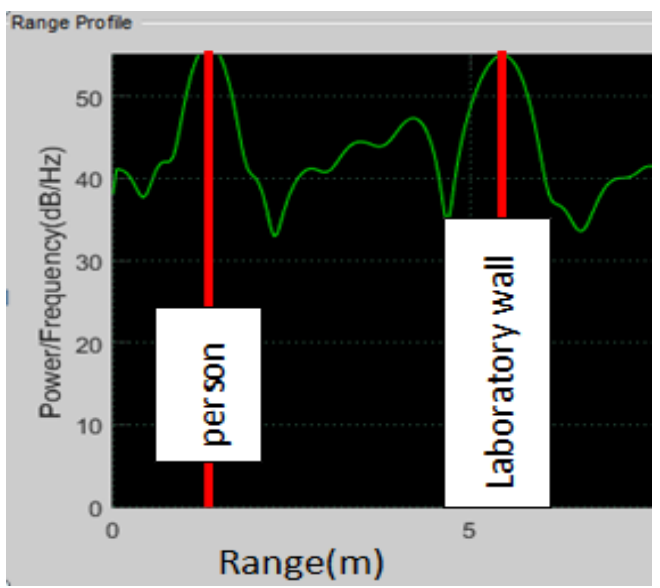

(a)Power/frequency against range

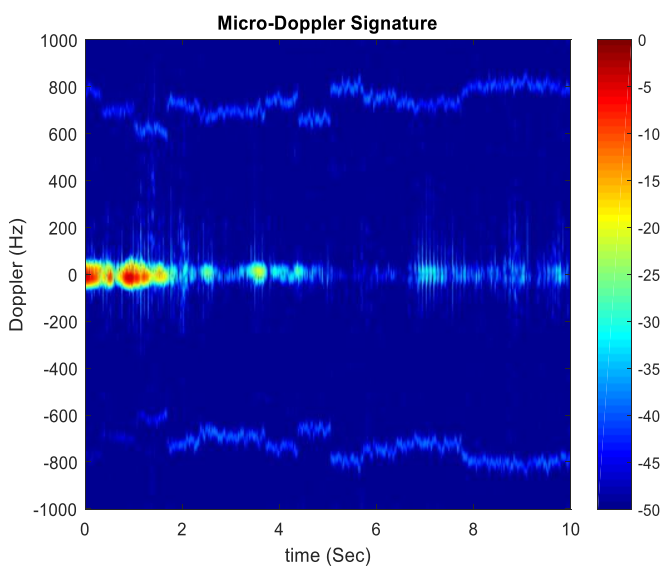

(b)Time against frequency

Figure 5. Laboratory wall $5.6 \mathrm{~m}$ and a standing person at $2.8 \mathrm{~m}$ from the radar

The movement of the person and his parts leads to the generate the Doppler and micro-Doppler, which is related to the parts velocities as in Figure 6. Where, the velocities have been appearing as in Figure 6 (a), which represents the different velocities of the Human body parts against the range. In this context, the Doppler frequency caused by these velocities is cleared in Figure 6 (b), where the appearance of these Doppler with different time delay caused by the movement of the person against the fixed radar.

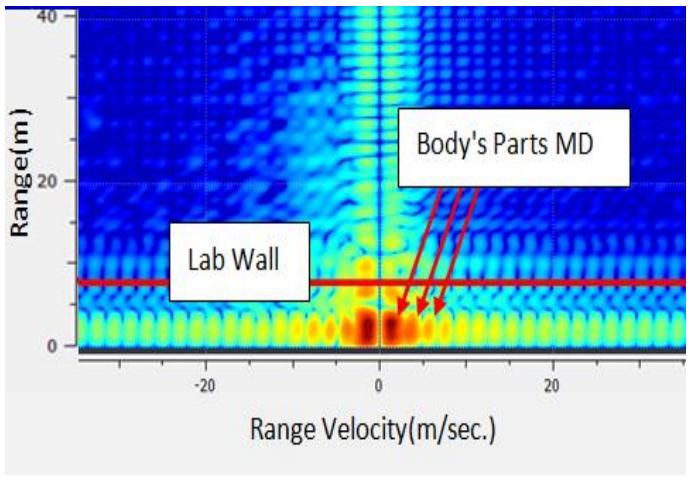

(a)Radial Velocity against range for moving person

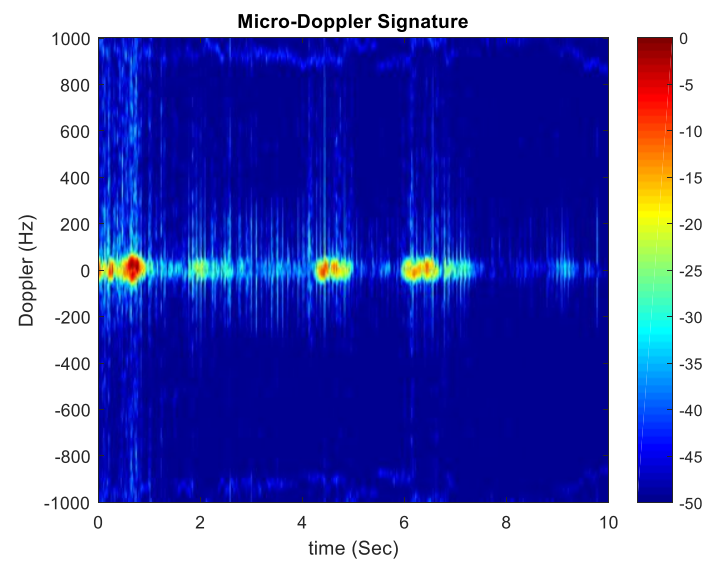

(b)Time against frequency

Figure 6. Laboratory wall $5.6 \mathrm{~m}$ and a moving person at $2.8 \mathrm{~m}$ from the radar 
The comparison between Figure 5 and 6, where, the difference is clear where the person appears without movement in Figure 5, while in Figure 6 the person is in motion. In this context, the dispersion of the reflected signal caused by the wooden wall has also appeared in the Figure 7 . While, Figure 8 represents the response and velocities range distribution of the body parts which is detected through that wall, where the parts which have a movement less than $12.5 \mathrm{~cm}$ from the core of the body (torso), it will appear as one moving object, because the operating frequency has wavelength is $12.5 \mathrm{~cm}$, and the noise which appears is by wall effected on the signal propagation .

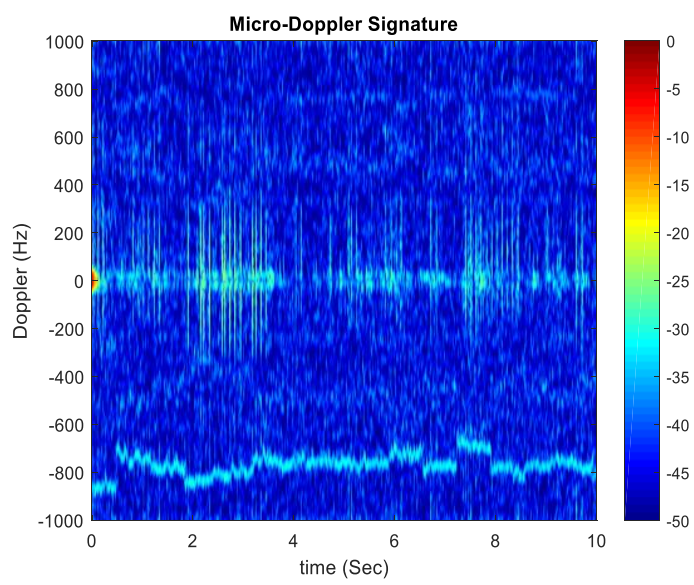

Figure 7 (a). Fixed person behind wood wall (2.8m) from radar

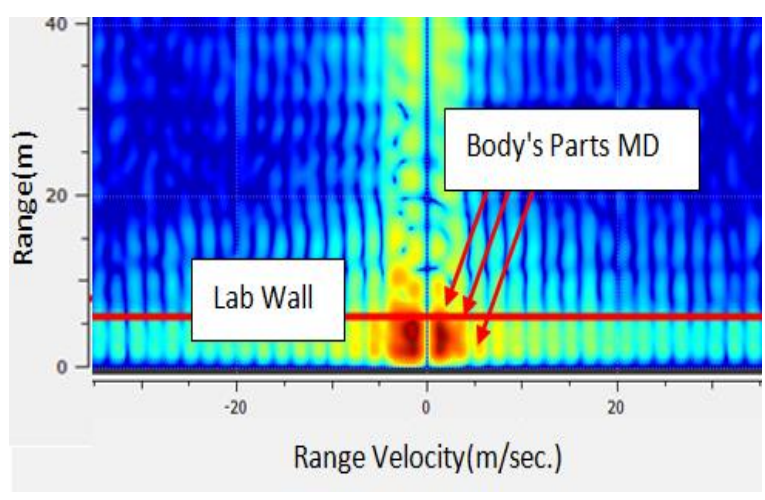

Figure 7 (b). Radial velocities against a range of moving person

Fortunately, the human on the bicycle is moving his legs, not his arm, therefore, this note has been used for recognizing between these movements. Also, the bicycle wheels appear its velocity as in Figure 8,

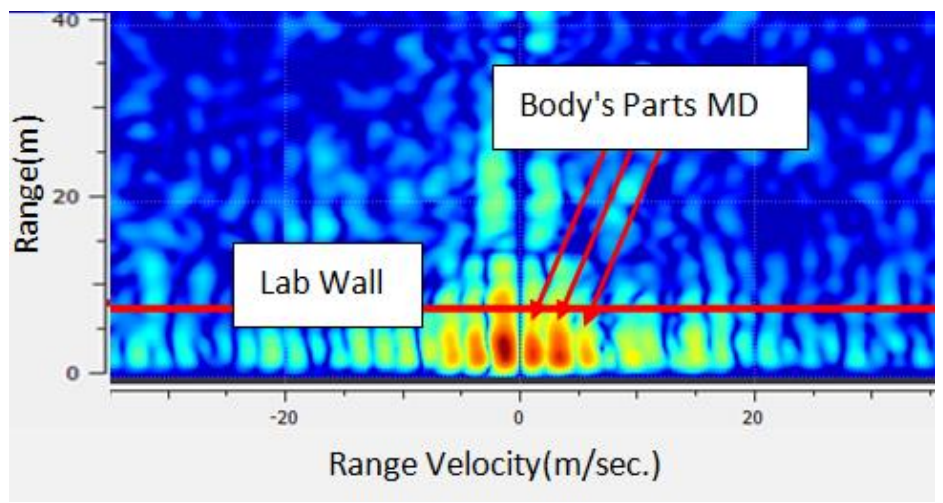

Figure 8. Radial velocities against a range for moving a person at $2.8 \mathrm{~m}$ with bicycle behind wood Wall from radar

Another wall has been examined, cork wall which is used widely in many applications as an isolation layer. The response of human movements behind the cork wall is shown in Figure 9.

The difference in responses between the recognition of human movements behind the wooden wall and the cork wall is caused by their internal structure. Where the internal structure of the wood is more suitable for detection at $2.4 \mathrm{GHz}$ than a cork wall. Figure 10 shown the effect of the internal wall structure, where the deviation of the propagation wave through these walls, especially through the cork wall, while the dispersion of the propagation wave through the wooden wall is clear. 


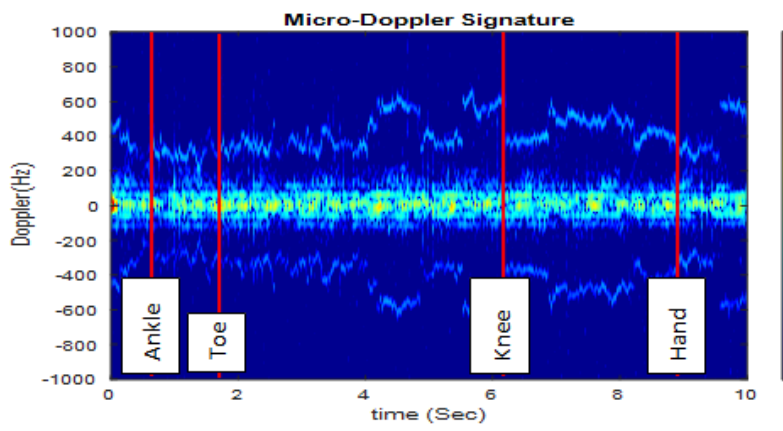

(a)Doppler frequency with time for human body parts during jogging

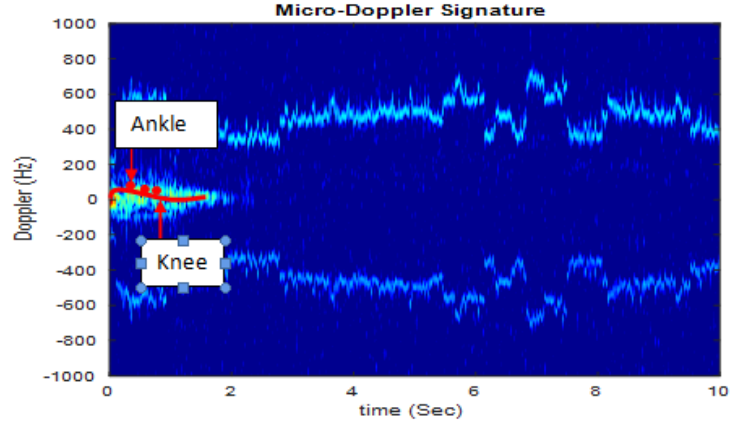

(b)Doppler frequency with time for parts of the human body while moving on a bicycle

Figure 9. Doppler frequency with time for parts of the human body through the wall

The difference in responses between the recognition of human movements behind the wooden wall and the cork wall is caused by their internal structure. Where the internal structure of the wood is more suitable for detection at $2.4 \mathrm{GHz}$ than a cork wall. Figure 10 shown the effect of the internal wall structure, where the deviation of the propagation wave through these walls, especially through the cork wall, while the dispersion of the propagation wave through the wooden wall is clear.

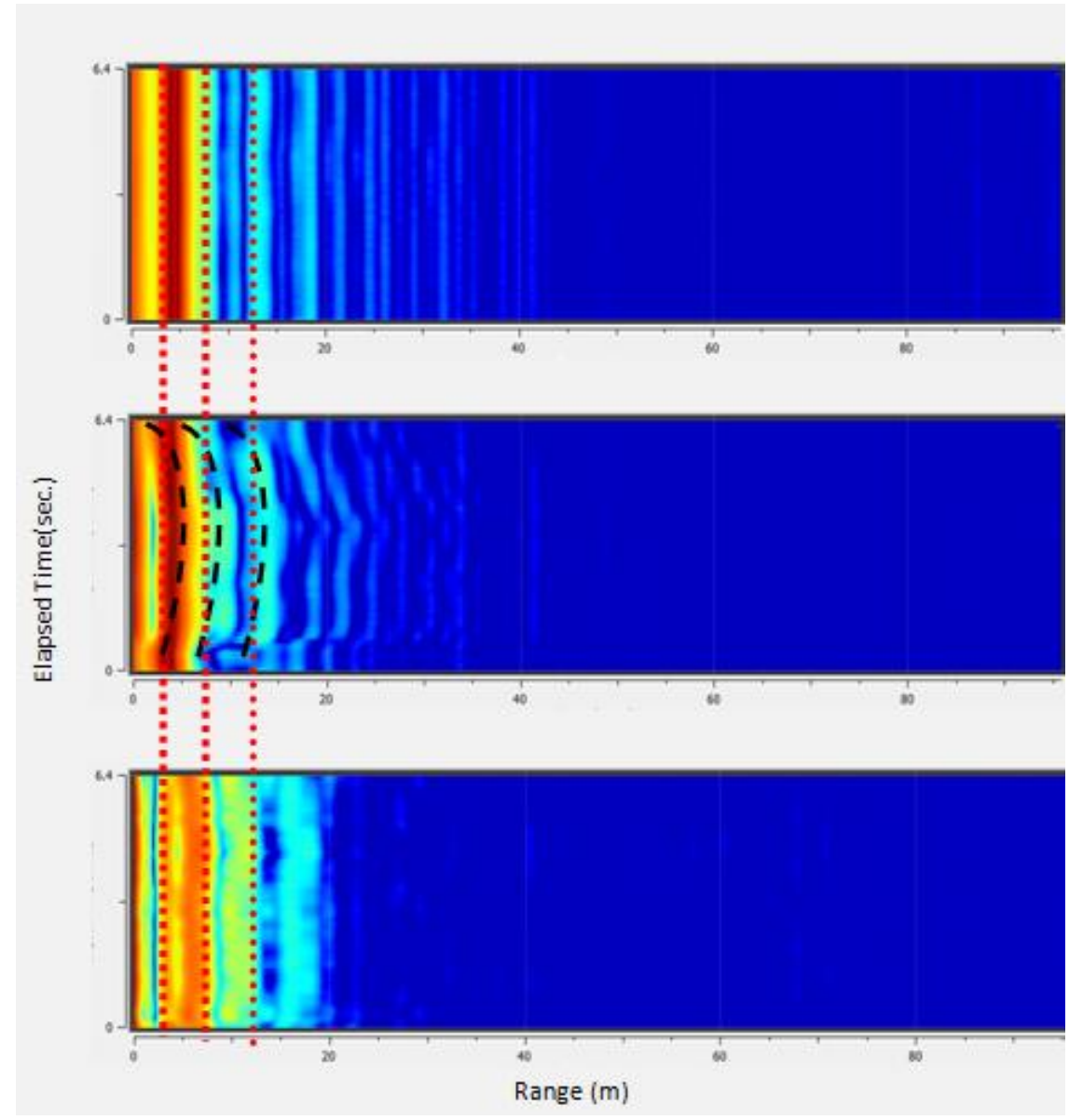

Figure 10. The effect of wall inner structural on the propagation wave through it, (a)without a wall, (b)cork wall and (c)wooden wall 
Therefore, to classify these three motions with and without wall a three SVM has been used as in proposed classifier, and the classification algorithm has been shown in Figure 11. Where, according to the velocity of the legs and arm as in Figure 2 and Table 2 where it is used as features, can classify the signal from human as; walking, running or move by bicycle. Where, if the arm is in motion the body is walking or running and classify between these two motions by the torso velocity (main Doppler). Well, if the arm is not moved and the legs are moved then the body is a move by bicycle.

Then the second and third classifier is working with the speed of the legs (Knee and Ankle) as features for human motion decision and classification among; walking, running or move by bicycle. Therefore, according to the human body parts velocities, the classification of different human moving status has been done by using SVM as a classifier and use the micro-Doppler effect as a feature, and the results as shown in Table 3.

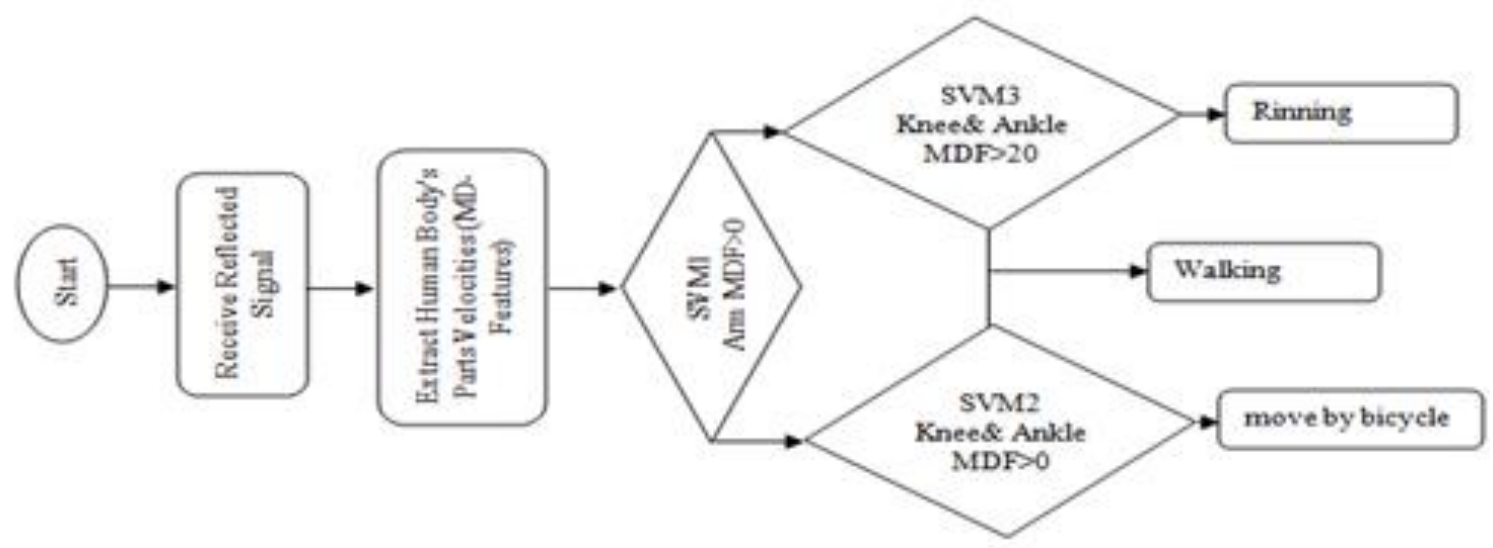

Figure 11. Classifier flowchart

Table 3. Recognition of Different Moving Bodies with Two Walls Type

\begin{tabular}{cccc}
\hline Moving body & $\begin{array}{c}\text { Reco.\% } \\
\text { without wall }\end{array}$ & $\begin{array}{c}\text { Reco.\% with } \\
\text { wooden wall }\end{array}$ & $\begin{array}{c}\text { Reco.\% with } \\
\text { Cork wall }\end{array}$ \\
\hline $\begin{array}{c}\text { Walking Human } \\
\text { Human on the }\end{array}$ & 98.7 & 95.4 & 94 \\
$\begin{array}{c}\text { bicycle } \\
\text { Running Human }\end{array}$ & 99 & 96.2 & 94.8 \\
\hline
\end{tabular}

\section{CONCLUSION}

Through-wall detection and classification are vital in many applications. While there are many important factors, have been effected on the detection and classification which are concluded from this experimental work. These factors are; signal strength, wall prosperities (internal wall structure), detection distance, carrier frequency, and the amount of displacement of moving body parts. Where $2.4 \mathrm{GHz}$ has been used, the detectable displacement in our experiments is $12.5 \mathrm{~cm}$, and it is achieved in somebodies parts in human walking, running and human on the bicycle. Therefore, the recognition which has been gained is $98.7 \%$ of the human walking and $98 \%$ for human running, while, $99 \%$ of human on the bicycle movement without walls. While, the recognition which is gained, with the wooden wall, is $95.4 \%$ for a human is walking, and $95 \%$ for a human is running, while, $96.2 \%$ for human moving by a bicycle. In another word, the recognition through the cork wall is reduced by $1.559 \%$ from that of the wooden wall, caused by its internal structure. In this context, the classification is based on the hand, Knee and Ankle movement as a human body part by using SVM as a classifier.

\section{ACKNOWLEDGEMENTS}

We would like to thank prof. Dr. Jawad K. Ali for his support and advice in accomplishing our work 


\section{REFERENCES}

[1] Vincent R. Radzicki, David Boutte, Paul V. Taylor, and Hua Lee. "Standoff CW Radar for Through-the-Wall Detection of Human Heartbeat Signature"s. IEEE Radar Conference (RadarConf), 2016.

[2] Shobha Sundar Ram and Angshul Majumdar. "Through-Wall Propagation Effects on Doppler-Enhanced Frontal Radar Images of Humans". IEEE Radar Conference 2016.

[3] Tian Jin, Yongping Song, Biying Lu and Zhimin Zhou. "A novel through-the-wall image formation for virtual aperture radar with electromagnetic wave refraction effect correction". URSI General Assembly and Scientific Symposium (URSI GASS), 2014”.

[4] P. Anil Kumar, B. Anuradha. Reflectivity Parameter Extraction From RADAR Images Using Back Propagation Algorithms". International Journal of Electrical and Computer Engineering (IJECE), vol 8, No. 5, Oct., part1, 2018.

[5] Pin-Heng Chen, Mahesh C. Shastry, Chieh-Ping Lai, and Ram M. Narayanan. "A Portable Real-Time Digital Noise Radar System for Through-the-Wall Imaging”. IEEE Transactions on Geoscience and Remote Sensing, 2012; 50(10).

[6] Dustin P. Fairchild and Ram M. Narayanan. "Micro-Doppler Radar Classification of Human Motions under Various Training Scenarios". SPIE Proceedings Vol. 8734, 2013.

[7] Xiaoxiang Liu, Henry Leung, and George A. Lampropoulos. "Effects of Non-Uniform Motion in Through-the-Wall SAR Imaging". IEEE Transactions on Antennas and Propagation. 2009; 57( 11).

[8] Ram M. Narayanan, Sonny Smith, and Kyle A. Gallagher. "A Multifrequency Radar System for Detecting Humans and Characterizing Human Activities for Short-Range Through-Wall and Long-Range Foliage Penetration Applications". Hindawi Publishing Corporation, International Journal of Microwave Science and Technology, Volume 2014, 21 pages, 2014.

[9] Jose M. Garcia-Rubia, Ozlem Kilic, Vinh Dang, Quang Nguyen, and Nghia Tran. "Analysis of Moving Human Micro-Doppler Signature in Forest Environments”. Progress In Electromagnetics Research, Vol. 148, 1\{14, 2014.

[10] Matthew Ritchie, Matthew Ash, Qingchao Chen and Kevin Chetty. "Through Wall Radar Classification of Human Micro-Doppler Using Singular Value Decomposition Analysis”. Sensors 2016, 16, 1401.

[11] Preethi K. Mane and K. Narasimha Rao. "Granular Mobility-Factor Analysis Framework for enriching Occupancy Sensing with Doppler Radar”. International Journal of Electrical and Computer Engineering (IJECE), Vol. 8, No. 2, pp. 979 988, April 2018.

[12] Carmine Clemente, Alessio Balleri, Karl Woodbridge and John J Soraghan. "Developments in target microDoppler signatures analysis: radar imaging, ultrasound and through-the-wall radar". EURASIP Journal on Advances in Signal Processing 2013, 2013:47

[13] Yinan Yang, Jiajin Lei, Wenxue Zhang and Chao Lu. "Target Classification and Pattern Recognition Using MicroDoppler Radar Signatures". IEEE Seventh ACIS International Conference on Software Engineering, Artificial Intelligence, Networking, and Parallel/Distributed Computing, 2006.

[14] Carmine Clemente, Alessio Balleri, Karl Woodbridge3 and John J Soraghan. "Developments in target microDoppler signatures analysis: radar imaging, ultrasound and through-the-wall radar". EURASIP Journal on Advances in Signal Processing, 2013:47, 2013.

[15] Aws Al-Qaisi, Saleh A. Khawatreh, Ahmad A. Sharadqah, Ziad A. Alqadi. "Wave File Features Extraction Using Reduced LBP”. International Journal of Electrical and Computer Engineering (IJECE), vol 8, No. 5, Oct., part1, 2018.

[16] Hussein Ali Aldelfy, Mahmood Hamza Al-Mufraji, Thamir R. Saeed. "Improved Key Frame Extraction Using Discrete Wavelet Transform with Modified Threshold Factor”. TELKOMNIKA (Telecommunication, Computing, Electronivs and Control), Vol.16, No.2, pp. 567 572, April 2018.

[17] Hameed R. Farhan, Mahmuod H. Al-Muifraje and Thamir R. Saeed. "A Novel Face Recognition Method based on One State of Discrete Hidden Markov Model”. IEEE Annual Conference on New Trends in Information \& Communications Technology Applications, 7 - 9 March 2017

[18] Hameed R. Farhan, Mahmuod H. Al-Muifraje and Thamir R. Saeed. "Using only Two States of Discrete HMM for High-Speed Face Recognition”. IEEE Al-Sadeq International Conference on Multidisciplinary in IT and Communication Science and Applications, IRAQ (9-10) May, 2016

[19] X Liu, H Leung, G Lampropoulos. "Effects of non-uniform motion in through-the-wall SAR imaging". IEEE Trans. Antennas Propagation. 57(11), 3539-3548 (2009).

[20] S Ram, C Christianson, Y Kim, H Ling. "Simulation and analysis of human Micro-Doppler in through-wall environments". IEEE Trans. Geosci. Rem.Sens. 48(4), 2015-2023 (2010).

[21] PH Chen, MC Shastry, CP Lai, RM Narayanan. "A portable real-time digital noise radar system for through-thewall imaging". IEEE Trans. Geosci. Rem. Sens. PP(99), 1-12 (2012).

[22] Fangmin Li, Chao Yang, Yuqing Xia, Xiaolin Ma, Tao Zhang and Zhou Zhou. "An Adaptive S-Method to Analyze Micro-Doppler Signals for Human Activity Classification”. Sensors 2017, 17, 2769.

[23] Dustin P. Fairchild, Ram M. Narayanan, Eric R. Beckel, Wai K. Luk, and Gerard A. Gaeta. "Chapter 5: Throughthe-Wall Micro-Doppler Signatures. IET Radar", Sonar and Navigation Series 34, Radar Micro-Doppler Signature Processing and applications, Edited by Victor C. Chen, David Tahmoush, and William J. Miceli, Printed in the UK by CPI Group (UK) Ltd, Croydon, IET 2014.

[24] R. Wilson. "Propagation losses through common building materials: $2.4 \mathrm{GHz}$ vs. $5 \mathrm{GHz}$ ". Technical Report, University of Southern California, August 2002. 
[25] HA-Hamza Reci, Tien Chinh Maï, Zoubir Mehdi Sbartaï, Lara Pajewski,and Emanuela Kiri. "Non-destructive evaluation of moisture content in wood by usingGround Penetrating Radar". Journal Geoscientific Instrumentation Methods and. Data Systems, 2016.

[26] Lamiae Hachad, Fatiha Mrabti, Hicham Ghennioui, Mohcine Zouak. "Pilot Decontamination over Time Frequency and Space Domains in Multi-Cell Massive MIMO System". International Journal of Electrical and Computer Engineering (IJECE), vol 8, No. 5, Oct., part2, 2018

[27] WWW. Ancortek Inc.

\section{BIOGRAPHIES OF AUTHORS}
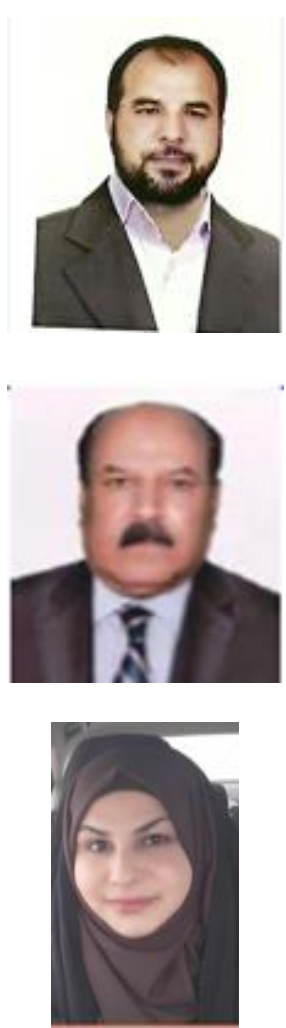

Thamir Rashed Saeed was Born in Baghdad, Iraq on february 10, 1965. He received the B.Sc. degree from military engineering college in Baghdad in 1987, the M.Sc. degree from military engineering college in Baghdad in 1994 and Ph.D. degree from AL-Rashed college of engineering and Secinec in Baghdad 2003. From 1994 to 2003, he worked with military engineering college in Baghdad as a member of teaching staff. From 2003 till now, he worked with the University of Technology in Baghdad as a member of teaching staff. Currently, he is Assis. Professor of electrical engineering at university of Technology and a head of radar research group in the Electrical Eng. Dept.. His major interests are in digital signal processing, digital circuit design for DSP based on FPGA, sensor network and Pattern Recognition.

Mahmuod Hamza AI-Muifraje received the B.Sc. in Electronic Engineering from University of Technology, Baghdad-Iraq in 1975. He received the M.Sc. and Ph.D. from Brunel university-UK in Electrical Engineering and electronics in 1979 and 1983 respectively. Currently, he is Assistant professor within the Department of Electrical Engineering at the University of Technology, Baghdad -Iraq. His main research interests include pattern recognition system, weightless neural networks, image processing and wireless sensor networks. Also, he is a member of radar research group in the Electrical Eng. Dept in UOT.

Ghufran M. Hatem received her B.Sc degree in Communications Technology from Najaf Technical College, Al-Najaf Al-Ashraf, Iraq in 2004. From 2004-2012, she was an engineer and a Lab Assistant at the same college. She received her MSC degree in Communication Engineering in 2012 and 2015. Currently, she is working to pursue her PHD degree in electronic and communication engineering from the Department of Electrical Engineering, University of Technology, Iraq. Her fields of interests are radar signal processing, microwave antenna miniaturization and design for RFID and wearable communication applications and neural network. Also, she is a member of radar research group in the Electrical Eng. Dept in UOT. 